\title{
ALGUNS TRATADOS SOBRE BIBLIOTECAS COMO FONTES PARA A HISTÓRIA DA ORGANIZAÇÃO PARA A MEDIAÇÃO DA INFORMAÇÃO
}

\section{ALGUNOS TRATADOS EN BIBLIOTECAS COMO FUENTES PARA LA HISTORIA DE LA ORGANIZACIÓN PARA LA MEDIACIÓN DE LA INFORMACIÓN}

\begin{abstract}
Giulia Crippa - giuliac@ffclrp.usp.br Livre Docente em Ciência da Informação pela Universidade de São Paulo (USP). Doutora em História Social pela USP. Docente do departamento de Educação, Informação e Comunicação da FFCLRP - USP.
\end{abstract}

\section{RESUMO}

Introdução: Uma reflexão histórica sobre a natureza do campo da organização do conhecimento e da informação que desloca o foco de uma leitura tradicional da história de bibliotecas e bibliotecários em busca de um quadro crítico e comparativo das lógicas de mediação informacional

Objetivo: Percorrer um itinerário de estudo que se desenrola entre fontes mais ou menos conhecidas, quais a Bibliotheca Universalis de Gesner e o Reformed Librarie-Keeper de John Dury, propondo sua leitura e, às vezes, releitura, que revela etapas e momentos significativos na construção e no desenvolvimento das idéias que se produziram e materializaram em formas de procedimentos bibliográficos e biblioteconômicos voltados à mediação.

Metodologia: Uso de fontes e revisão crítica de literatura.

Resultados: O século XIX revela um afastamento de uma linha de raciocínio que envolve os bibliotecários e suas produções bibliográficas como construção colaborativa com os usuários em suas pesquisas e recuperação, lá onde os século XVI e XVII revelavam uma preocupação com as particularidades do sujeito conhecedor, mas, em primeiro lugar, suas maneiras, formas de adquirir o conhecimento.

Conclusões: Os estudos biblioteconômicos, através do estudo do passado em que bibliotecas e bibliotecários se inserem em um tecido social e cultural de produção e circulação do conhecimento, podem desenvolver um percurso que, voltado para a 
organização da informação descobre o peso que ela possui como elemento fundamental da mediação.

Palavras-chaves: Biblioteconomia. Bibliografia. Conrad Gesner. John Dury.

\section{INTRODUÇÃO}

Nos primeiros anos do século XVII verifica-se um fenômeno inédito. As nações da Europa setentrional, em tudo equiparadas, culturalmente tanto nas ciências como no humanismo, aos moldes renascentistas gerados um século antes nos territórios italianos, se conscientizam das carências de seus sistemas bibliotecários, que não se encontravam à altura das exigências dos leitores em um mundo produtor, de maneira ampla, de uma cultura impressa.

Para termos um exemplo "visual" do possível descompasso entre inovação provocada pela revolução impressa e estrutura de uma biblioteca, podemos recorrer à famosa gravura da biblioteca de Leyden de 1610, obra de Woudanus ${ }^{1}$, que nos mostra uma sala iluminada por amplas janelas entremeadas por pinturas, com exclusão da parede de fundo, ornamentada unicamente por um baixo relevo. No centro da sala se observam onze estantes alinhadas perpendicularmente às janelas, dispostas em duas fileiras.

A parte superior das estantes apresenta os livros, acorrentados à madeira, que podem ser consultados no plano inclinado à altura de mesa, enquanto a parte de baixo, vazada, apresenta um simples apoio para os pés dos leitores. Cada um dos vinte e dois móveis devia conter, provavelmente, uma quantia de livros superior aos quarenta e poucos representados em fila única pelo gravurista Jan Cornelius Woudanus, mas mesmo multiplicando um pouco a quantia, o espaço proposto hospedaria pouco mais que três mil volumes.

E, com efeito, o catálogo alfabético orgulhosamente publicado em sua forma impressa, com o nome de Nomenclator em 1595, considerava que esse fosse 0 numero de livros necessários para suprir às exigências do conhecimento inteiro (BOTTASSO, 1984, p. 48). Nas estantes da gravura, são visíveis as divisões do

\footnotetext{
${ }^{1}$ Disponível em: http://eduscapes.com/history/modern/leydon.jpg
} 
conhecimento e a importância relativa dedicada a cada ramo dele: uma estante para a matemática, duas, respectivamente, para a literatura e a filosofia, seis à teologia e, do outro lado do corredor, quatro para a história, duas à medicina e cinco ao direito.

Se quisermos entender as motivações e os critérios de serviço na impostação e na ordem das bibliotecas modernas, precisamos dedicar um pouco de atenção à documentação disponível para a Europa daquela época, que enunciava programaticamente a aspiração de reunir grandes coleções "universais" do patrimônio cultural colocado em circulação através dos livros impressos, aspiração que começou a se concretizar no começo do século XVII.

No âmbito dos estudos sobre equipamentos culturais e meios de transmissão cultural não faltam, com certeza, produções reflexivas de natureza histórica. $O$ paradigma destes estudos tem se pautado, aos poucos, por perspectivas cada vez menos preocupadas em definir tipologias "em evolução" dos centros de informação (bibliotecas, museus, arquivos e, hoje, tecnologias digitais) e cada vez mais para o entendimento dos sistemas que embasam a constituição, organização, circulação e apropriação dos conhecimentos, dos quais os centros de informação são elementos essenciais.

Autores como Roger Chartier (1999), Robert Darnton (2010), Peter Burke (2003) entre outros, cada um com sua metodologia histórica, nos permitem entender de que maneira o passado operou suas escolhas culturais através de seleções, ordenações e acessibilidade à informação registrada em algum suporte.

O olhar de escolas históricas voltadas para uma pesquisa indiciaria, como propõe Carlo Ginzburg (2004), ou para os estudos de uma História Cultural, como no caso dos já citados Chartier, Darnton ou Burke, apresentam perspectivas renovadas sobre as atividades bibliográficas e de catalogação, propondo abordagens inéditas de análise dos sistemas de produção, seleção, organização e mediação cultural de objetos aparentemente já amplamente estudados: os livros, as coleções, os registros materiais que, em algum momento, se tornaram dignos de serem preservado e disseminados para a constituição da ciência moderna. Esta história possui metodologias próprias, objeto de discussão do campo histórico, e não da Ciência da Informação, mas cujos resultados a colocam na fronteira disciplinar das duas áreas, assim como discutido por Crippa (2012). 
A reflexão histórica sobre a natureza do campo da organização do conhecimento e da informação desloca o foco de uma leitura tradicional da história de bibliotecas e bibliotecários, para se tornar uma história das relações estruturais entre saberes, organização dos conhecimentos e poderes, representados pelas redes institucionais geradoras, conservadoras e divulgadoras desses saberes.

Com efeito, a organização da informação não é dada a priori, mas é o resultado de formações históricas voltadas para a manutenção de instituições que conservam e disseminam, conforme aquelas que hoje chamamos de "políticas da informação", instrumentos e materiais para um conhecimento socialmente compartilhado. Torna-se necessária uma reflexão em relação à figura e ao papel dos responsáveis pela representação dos documentos e produtos culturais de cada época, reconstituindo tarefas e responsabilidades em relação à manutenção e à renovação das estruturas institucionais da sociedade e da cultura. É, de fato, através de escolhas classificatórias e de representação que se torna possível a manutenção dos conhecimentos.

Certo é que o campo dos estudos históricos sobre as bibliotecas como lugar de destaque de um movimento que, ao longo de vários séculos, leva a uma Sociedade da Informação, ainda propicia um amplo espaço para a pesquisa, desde que indagadas as bibliotecas através da transmissão e da renovação dos gestos de seus ofícios. Neste sentido, um dos caminhos que ainda podem ser trilhados diz respeito à busca de um quadro crítico e comparativo das lógicas de mediação informacional, em que os elementos episódicos ligados a realidades específicas não são propostos para reiterar uma história ou uma teoria unificadora das bibliotecas, pois é este material pontual e específico que a documentação bibliográfica oferece.

Sem querer preencher o vazio que uma história unificadora traz, enquanto pouco satisfaz para o entendimento do funcionamento das bibliotecas em seus contextos sociais, econômicos e políticos, mas considerando as mesmas como pontos de destaque na estruturação do conhecimento através de suas grades classificadoras dos registros informacionais e de sua acessibilidade, é possível percorrer um itinerário de estudo que se desenrola entre fontes mais ou menos conhecidas, propondo sua leitura $e$, às vezes, releitura, que revela etapas e momentos significativos na construção e no desenvolvimento das idéias que se produziram e materializaram em formas de procedimentos biblioteconômicos. 
O que estrutura, neste sentido, a relação de organização e acesso em uma biblioteca, sempre foi o conjunto de lógicas e de procedimentos de mediação através dos catálogos. Com efeito, interpretamos 0 ato bibliográfico como ato informacional, enquanto a biblioteconomia pode ser vista como a práxis de constituição, de organização, de gestão de bibliotecas por longo tempo em seu paradigma físico, considerando também as necessidades logísticas que elas impõem. A bibliografia, nesta perspectiva, pode ser vista como atividade biblioteconômica que permite que se estabeleça o contato entre os usuários e o mundo das noções e dos conceitos registrados em documentos. Para a realização deste contato, são necessários mecanismos de coleta, ordem, conservação, acesso e circulação desses documentos, gestos que somente a constituição de lugares que podemos chamar de bibliotecas torna possíveis.

Em uma revisão da literatura, raras são as obras que tratam da biblioteca de maneira sistemática antes do século XVIII. Antes da prensa de Gutenberg, podemos nos ancorar em alguns autores que, de maneira geral, organizam os conhecimentos na base dos materiais manuscritos, fornecendo os modelos da biblioteca cristã.

Para encontrarmos propostas de organização bibliográfica e biblioteconômica mais estruturadas precisamos chegar ao século XVII, onde se assiste a uma proliferação cada vez maior de obras que tratam de bibliografia dentro das bibliotecas.

O que queremos enfocar nesse artigo são alguns aspectos da bibliografia pelo prisma histórico, para entendermos que paradigmas a mediação moldou. Para isso, procuraremos observar alguns autores que, apesar de frequentemente citados na história das bibliotecas, ainda não foram enfocados pelo prisma da mediação. Para isso, observaremos alguns aspectos do trabalho de Gesner, naturalista e bibliotecário, e de John Dury, encarregado da organização da biblioteca universitária de Oxford durante a revolução inglesa. O primeiro, autor do século XVI, e o segundo, do século XVII, apresentam uma forte preocupação à circulação da informação por meio dos catálogos e, principalmente, o papel essencial do bibliotecário enquanto mediador.

É preciso ressaltar que não se trata de obras que conduzem, como em uma "evolução", a uma biblioteconomia única e integrada, na qual se desenvolvem os mesmos protocolos para regular as operações e os procedimentos bibliotecários. No 
lugar dessa história universal da evolução das bibliotecas, preferimos procurar os critérios que embasam a competência, funcionalidade e eficiência das estruturas de mediação entre coleções e usuários.

\section{Entender a mediação da informação na história: Conrad Gesner e a Bibliotheca Universalis}

Para os estudiosos que viveram na modernidade incipiente, era possível fechar em fronteiras aceitáveis o patrimônio dos conhecimentos humanos, assim como era possível arquivar a multiplicidade e diversidade do mundo.

Com base em um sistema de analogias, aos poucos se assiste ao deslocamento para a ênfase na lógica de novos sistemas classificatórios para a partição e ordenação das ciências, emparelhada à classificação bibliográfica na constituição de uma hierarquia não somente de ordem filosófica, mas sim prática, pois na elaboração dos instrumentos bibliográfico de classificadores de livros e bibliotecas, até os enciclopedistas franceses do século XVIII, adquirem grande peso não somente as particularidades do sujeito conhecedor, mas, em primeiro lugar, suas maneiras, formas de adquirir o conhecimento. A ciência ocidental se configura como ato de confiança na fixação das condições objetivas de pesquisa e na sua capacidade de espelhar a realidade a ser pesquisada, em relação ao que pode ser pesquisado e às faculdades de quem pesquisa. As ciências e suas relações e métodos, portanto, emergem como resultado de uma visão do mundo que pode ser conhecido e representado. Com base na confiança nesse a priori, foi Francis Bacon que, fixando as condições objetivas da pesquisa, fornece um quadro geral dos campos de estudo e um esquema disciplinar, fundamentados nas três faculdade de apreensão da mente, a Memória, a Imaginação e a Razão, até hoje bases epistemológicas da ciência ocidental, silenciadas na caixa preta de nossas classificações biblioteconômicas. O lluminismo, por sua vez, acentua a faculdade da Razão, com um movimento que, até os nossos dias, tende a deslegitimar as outras duas faculdades como confiáveis na apreensão do mundo. De fato, uma observação das principais linguagens documentárias de natureza enciclopédica revela essa impostação filosófica.

Todavia, um dos primeiros autores a enfrentar os problemas novos apresentados pelos livros impressos foi o alemão Conrad Gesner que, em 1545 
publica, em Zurique, um Catalogus omnium scriptorum locupletissimus, in tribus linguis, latina, graeca et hebraica: extantium et non extantium, veterum et recentiorum in hunc usque diem, doctorum et indoctorum, publicatorum et in bibliothecis latentibus. Uma primeira tentativa de bibliografia completa nas três línguas da cultura sacra e profana, melhor conhecido como Bibliotheca Universalis.

Trata-se de seu grande trabalho bibliográfico, um catálogo alfabético-nominal em que as obras são registradas com o nome do autor, ladeado pelas Pandectae (1549), catálogo sistemático das obras, que são elencadas num nível mínimo de lugar ordenado em vinte e umas classes de disciplinas. As duas obras visam evidenciar, registrar e sistematizar tudo que havia sido escrito na literatura disponível da época.

Conforme Sabba (2012), a Bibliotheca Universalis não é simplesmente um "prontuário" alfabético, mas um projeto bibliográfico que consiste no alistamento do que está publicado e de um repertório em ordem sistemática. Gesner coloca em pauta mais de cinco mil autores que escreveram nas três línguas, oferecendo uma coleção de teses e compêndios de uma tradição literária que se estende ao plano semântico, assinalando valores de resumo sobre tudo aquilo de que se tinha conhecimento. Em um terceiro momento, Gesner pretendia publicar um índex alfabético dos sujeitos que se encontravam articulados nas seções disciplinares do catálogo sistemático representado pelas Pandectae, mas seu falecimento prematuro impediram a realização dessa parte.

Um dos maiores estudiosos de Gesner, Serrai (1990), explica que no prefácio da primeira parte da obra o autor oferece, ao lado do panorama editorial, suas intenções, a estrutura e o método de trabalho. Relevante, para nós, é a afirmação de Gesner sobre a necessidade de se preparar um inventário de fácil consulta do patrimônio escrito existente. Para tanto, Serrai (1990) individualiza quatro níveis de categorias: o autor, que deve ser entendido como chave de acesso ao repertório; a obra, enquanto objeto específico da bibliografia; o texto, como referencia às fontes; a edição, em que se indicam o tipógrafo e o editor.

Gesner está interessado, principalmente, em fornecer ao leitor todos aqueles elementos que podem permitir a escolha em termos de aquisição. Nesse sentido, ele se propõe não a relatar sobre tudo que já fora escrito mas, sim a orientar nas aquisições. 

mediação da informação

A Bibliotheca universalis representa um unicum na história da bibliografia, pois ninguém, nem antes, nem depois, conseguiu elaborar e publicar um catálogo dessa natureza e tal unicidade tornou a obra rapidamente muito procurada, não somente por sua raridade e preciosidade mas também como referencia e suporte para a constituição de novas bibliotecas, tanto públicas como particulares e como modelo de catálogo para sua organização. Se propõe, também, como vademecum e instrumento de consulta para os estudiosos de qualquer disciplina ou ciência, pois contempla também todas as disciplinas particulares para as quais as Pandectae forneceriam itinerários específicos e especializados na base dos mesmos esquemas e percursos que regulavam a matéria, os métodos e os acessos das próprias disciplinas.

Em síntese, as principais inovações da obra de Gesner se encontram no fato de ser um repertório universal nas três línguas (vale ressaltar que as línguas vernáculas, por ser "locais", não representam essa universalidade), um resumo documental que procura

delinear um balanço de todo o passado literário, científico e histórico da civilização ocidental e de oferecer um inventário de tudo aquilo que, na primeira metade de 1500 se apresentava como a herança cultural da Europa (SERRAI, 1990, p. 71).

A universalidade da obra se encontra na seleção não somente de obras eruditas, como também nas dos indoctos, desde que relevantes, bem como na falta de barreiras entre obras impressas e manuscritos.

A Bibliotheca pode ser vista ao mesmo tempo como catálogo, no sentido de lista bibliográfica por autores, e como possível coleção de livros, isso é: uma instituição (pública ou particular) destinada à reunião física de um determinado numero de livros dedicados ao estudo, à leitura e ao colecionismo.

Serrai (1990) e Sabba (2012) convergem na observação de que, ao longo da realização da Bibliotheca Universalis as funções enciclopédicas e relativas à exposição da história literária foram se reduzindo, destacando a função mais de enumeração e documentária de um elenco de livros. Gradualmente, os aparatos exclusivamente bibliográficos - entendidos como descrição sumaria em forma de índex das obras e das edições, como são hoje em dia entendidos - e deixando cada 
vez mais como pano de fundo as contribuições e os contextos eruditos, disciplinares, históricos e literários.

Observa-se, assim, o surgimento da separação, pragmática porém empobrecedora, entre a matriz intelectual e semântica da bibliografia e seus frutos em termos de elencos e listas cada vez mais áridos e superficiais, com grave danosa prática bibliotecária. Escopo da Bibliotheca Universalis, como proposto no prefácio, era de ser uma coleção de documentos e testemunhas que apresentam a estrutura, o programa e o conteúdo das obras, porém, por questões editoriais de redução de custos, esses elementos se tornam mínimos conforme as letras se seguem.

Com esses elementos básicos relativos à obra de Gesner, podemos agora elaborar algumas ponderações acerca da relação que ela estabelece com a idéia de mediação. A apresentação marcada e ordenada com finalidade de prontuário, assim como acontecia com os dicionários, não se limitava aos nomes dos autores, incluindo também o título de cada obra, listada de maneira distinta e oferecendo fácil acesso à consulta, de modo a ser rapidamente selecionada e individualizada. Por outro lado, a organização e a disposição das notícias contidas no prontuário constituíam não somente um método eficaz para a busca, como também um baluarte contra a angustia, contra um certo temor que podia ser gerado pelo tamanho dos volumes.

Um entendimento de Gesner, que nos parece importante realçar como elemento voltado para a mediação, é de que a Bibliotheca Universalis teria a função de impelir os poderosos e mais abastados a fundar novas bibliotecas e que, através delas, chegassem às gerações seguintes os resultados da literatura e da ciência dos quais desfruta a humanidade. Não é por acaso que, no prefácio, um amplo espaço é dedicado à preocupação com a perda dos livros e com a necessidade de organizar um repertório que impeça tais perdas:

Itaque volui etiam ipse hac in parte quantumcunque labore ac studio effectum dare valerem, in usum humanae vitae conferre: quod pro unius hominis conditione, hoc volumine publicato, si non perfeci, non infelicitater tamen, ut spero, inchoavi: viam aperui \& magnam alijis ocasionem praebui, qua facile divites aut príncipes viri Bibliothecas instituant, libris ad posteritatem transmittendis necessarias. (GESNER, apud SERRAI, 1991, p. 282). 

mediação da informação

Nesse sentido, é notável a afirmação de Gesner sobre a importância das bibliotecas públicas, enquanto somente elas fornecem a garantia necessária à tutela e preservação do patrimônio escrito. Estabelece, assim, um dos princípios fundamentais para a instituição e manutenção de uma estrutura bibliográfica: a inseparabilidade da esfera material do livro de sua esfera intelectual vincula, de maneira firme e permanente, as condições de existência e acesso das obras como elementos para o espírito, na medida em que elas resultam inelutavelmente conectadas com suas hipóstases físicas, isso é, com os registros lingüísticos gravados em suporte físico. Gesner individualiza o nexo entre biblioteconomia e bibliografia, isso é, entre a existência de um lugar chamado biblioteca em termos de constituição, organização e gestão das coleções e a produção de mecanismos de acesso e circulação dos documentos para estabelecer o contato entre os usuários com suas exigências. Esse nexo entre bibliografia e biblioteconomia marca a natureza e a função da instituição bibliotecária em seus dois pontos fundamentais, de preservação e de serviços: a função de preservação, para Gesner, no século XVI, é preciosa na medida em que as bibliotecas oferecem o acesso e uso dos bens culturais que não podem ser avulsos de um conjunto de necessidades intelectuais (SERRAI, 1990).

Assim, entre a Bibliotheca Universalis e as bibliotecas enquanto espaços físicos existe a possibilidade de interação, contida no próprio repertório bibliográfico e a existência dos volumes reunidos em um espaço: o uso da obra de Gesner como catálogo de busca e acesso às obras e suas edições, pois pode ser utilizada em qualquer biblioteca, permitindo anotações de colocação dos livros nas margens e sua ampliação com novos registros.

A troca entre biblioteconomia e bibliografia se tornava, assim, operacional e poderia continuar até os nossos dias. Todavia, isso não aconteceu por uma interpolação conceitual que disseminou a convicção de que os diversos substratos documentários e as novas formas de comunicação e elaboração das informações introduziram modificações que não podem mais ser entendidas nas relações entre a lógica informacional bibliográfica e a lógica documentária física, isso é, biblioteconômica. 
Alguns tratados sobre bibliotecas como fontes para a história da organização para a mediação da informação

\section{A organização da biblioteca de Oxford na perspectiva da mediação: John Dury}

Como afirmado, os estudos históricos no campo da biblioteconomia e da documentação recorrem, cada vez com mais freqüência, aos ensaios produzidos por historiadores preocupados em entender as formas de estabelecimento dos regimes de conhecimento e informação em realidades observadas tanto dentro de um mesmo contexto histórico (sincronicamente) como em épocas distantes entre si (diacronicamente), pois tornou-se necessária uma revisão do estatuto que coloca a biblioteconomia em um contexto construído, principalmente, ao longo do século XIX.

Observam-se, nas referencias mais numerosas, algumas personalidades privilegiadas em termos de elaboração das ferramentas, práticas e ideários relativos às bibliotecas. In primis, se destaca Gabriel Naudé que, graças ao seu tratado Advis pour dresser une bibliothéque de 1627 (1992), tornou-se umas das referencias na reflexão histórica sobre as bibliotecas. Escolha sem dúvida interessante, pois, com efeito, se trata e uma obra que revela uma série de sugestões e regras para realizar uma estrutura de biblioteca funcional. O autor se dedica a todos os aspectos da biblioteca, desde a sistematização de seus conteúdos até a orientação ideal das janelas e os móveis melhores para a conservação dos materiais. Estranhamente, o tratado é apontado como relevante na medida em que afirma a necessidade da biblioteca como espaço público, deixando de lado um esclarecimento sobre o que significa público aos tempos de Naudé, criando assim um anacronismo que deve ser resolvido. Para esclarecer a idéia de biblioteca pública precisa observar que houve um deslizamento semântico da palavra "público" ao longo do tempo. Anteriormente ao século XVII, público designava aquilo que era de uso comum, portanto livre (nesse sentido, o ar é público, assim como a água). Com a insurgência das monarquias e dos Estados Absolutistas, contexto em que vive e atua Naudé, público designa o que é do Estado. Devemos esperar o século XIX para que o termo aponte aquilo que pertence e é útil para o público entendido como "povo", e é somente nesse momento que a biblioteca adquire sua face educativa e social. Neste sentido, talvez seja necessário matizar a relevância de Naudé dentro de seu quadro histórico.

Quadro histórico que pode ser associado e pensado em relação a outra realidade, a Inglaterra do século XVII, e a uma outra personalidade, que poucas vezes é referendada nas histórias das bibliotecas e dos bibliotecários. Se trata de John Dury, cuja referencia mais recente se encontra em três breves parágrafos do 
Alguns tratados sobre bibliotecas como fontes para a história da organização para a mediação da informação

primeiro volume de Uma história social do conhecimento (BURKE, 2003), relacionado às atividades de reforma educacional e bibliotecária.

Nascido na Escócia em 1596, Dury estudou em Leyden e em Oxford, para ser ordenado ministro protestante em Colônia. Dury representa, ao lado de figuras como Hartlieb e Comênio, os ideais filosóficos da Revolução Inglesa. Os três intelectuais, de fato, trabalharam juntos na elaboração de uma proposta de reforma educacional face o papel que a Inglaterra teria que desempenhar na ocasião do advento do Milênio de paz e prosperidade, época delineada através das interpretações bíblicas do tempo (DELUMEAU, 1997). Enquanto Samuel Hartlieb é conhecido como reorganizador dos modelos científicos e teológicos do conhecimento, Comênio se destaca pelas suas reformas no campo da educação. Dury, por sua vez, buscou caminhos para implantar as visões baconianas no campo das bibliotecas. Os três se encontraram em Londres em 1641, tentando fundar uma universidade. A proposta, apesar de todo o apoio garantido pelo parlamento, pelo próprio Cromwell e pela Igreja, não se realizou pelas contingências da revolução. Os três elaboraram listas de planos práticos, dentro de sua visão milenarista, para melhorar e reformar muitos aspectos da vida humana, através do avanço do conhecimento a ser realizado por reformas na escola e, principalmente no caso de Dury, por uma reforma na própria organização dos registro do conhecimento. Neste sentido, as melhorias envolvem a biblioteca, enquanto referencia básica para a preparação ao Milênio.

Dury viajou pela Europa inteira e teve ocasião de visitar, entre outras, a rica biblioteca de Wolfenbuttel do Duque de Brunswick, que ainda será o lugar de trabalho de Leibniz e se tornará, sob a direção de Lessing como bibliotecário, uma biblioteca exemplar para as Luzes.

Com a fuga do rei Carlos I, suas posses se tornaram objeto de discussão: queimar os livros e as obras de arte? Vendê-los? A salvaguarda dos livros garantida, em 1650 eles foram confiados a Dury que, como primeiro ato, os realocou na Capela Real, construída para as núpcias do rei (onda ainda se encontra parte do acervo da Universidade de Oxford). Em seguida, dedicou-se à organização do livros.

Em um panfleto de 1646 ele propõe a criação de um "Office of Address", um serviço de informação para quem sentisse necessidades espirituais e de materiais de estudo. Encabeçaria este centro de informação um bibliotecário chefe, cujas tarefas seriam as de negociar e trocar os materiais para favorecer a aprendizagem 
Alguns tratados sobre bibliotecas como fontes para a história da organização para a mediação da informação

e, para os estudiosos, favorecer o acesso aos livros e manuscritos que deseja ler (CARICCHIO, 2010).

Em 1650 publica o panfleto mais relevante para nosso entendimento da sua idéia de biblioteca, The Reformed Librarie-Keeper (RLK), opúsculo sobre as bibliotecas em que enumera os problemas práticos a serem resolvidos e interpretados em uma visão geral de bibliotecário, biblioteca, escola e Igreja, sempre em razão do advento do Milênio, presença constante como pano de fundo. Para nós, este aspecto religioso é uma mera curiosidade, enquanto as reformas práticas que o autor propõe, ainda que em pouco ou nada tenham sido realizadas, nos interessam na medida em que sustentam, ainda hoje, um modelo de biblioteca e de biblioteconomia.

Em seu RLK Dury se refere, principalmente, às bibliotecas universitárias, que devem disponibilizar seus acervos para todos os estudiosos. Para ele,

[...] a função correta do bibliotecário em uma universidade deveria ser repensada e, no final, este ofício na minha concepção é manter um estoque público de aprendizagem que se encontra nos livros e manuscritos (RLK, p. 17).

Princípio fundamental para Dury é o da utilidade das bibliotecas:

É verdade que uma boa biblioteca não é somente uma decoração ou um crêdito para o lugar onde se encontra, mas uma commodity para o público: todavia, na verdade, não é mais do que um corpo defunto da maneira como ela é constituída atualmente, comparada com o que poderia ser se fosse animada por um espírito público para se manter e ser usada e ordenada (RLK, p. 18)

Concentrando-se nas questões práticas de organização e de administração, Dury enaltece a função do bibliotecário como agente educativo, alem é claro, de sua missão cristã. É relevante realçar que, considerando ou menos a perspectiva milenarista, o papel do bibliotecário era, para Dury, o de disponibilizar os materiais ao público, coisa que, pelas palavras do próprio autor, não devia ser prática comum, precisando, assim, de uma reforma. Par Dury, o bibliotecário não deve, de maneira alguma, limitar-se à guarda dos livros, mas disponibilizá-los. Neste sentido, pode ser observado como, em uma perspectiva de história mais "tradicional", se costuma relatar de maneira simplista como a biblioteca de hoje se coloque em termos 
Alguns tratados sobre bibliotecas como fontes para a história da organização para a mediação da informação

inovadores em sua "abertura" para os usuários, contrapondo-se a um modelo pouco preocupado com os usuários e muito com a guarda até recentemente. Pode-se observar como, na verdade, a preocupação com o acesso ao conhecimento guardado por parte dos usuários, até agora, é tema central na proposta de Dury que frisa um papel de bibliotecário hoje considerado primordial na profissão: disponibilizar o conhecimento através do acesso à informação. Para tanto, Dury coloca como eixos centrais para a mediação o Catálogo e o : "e para realizar tudo isso, em primeiro lugar deve ser feito um catálogo dos tesouros a ele confiados, que é todos os livros e manuscritos, de acordo com os títulos e onde se encontram." (RLK, p. 18). Sem propor um sistema de referencia numérico, marca todavia a importância das anotações para a localização a serem inseridas no próprio catálogo.

Dury não somente se preocupa com as mediações necessárias para o uso das bibliotecas por parte dos usuários. O bibliotecário é mediador também em relação às "metodologias" para as aquisições. Alem de boas relações fora e dentro das universidades, das bibliotecas e de outros circuitos intelectuais nacionais e internacionais, ao bibliotecário é confiada a tarefa de mediar a tramitação de pedidos e sugestões dos estudiosos das várias áreas do conhecimento: "portanto, ele deve negociar com aqueles que, no país e no exterior, se encontram dentro e fora das universidades; deve ter relações para saber tudo aquilo que, em qualquer medida, oferece suprimento para as faculdades" (RLK, p. 19).

É nesse sentido que, para ele, o catálogo deve ser construído, um lugar claro e simples para a recuperação dos materiais por parte dos usuário e uma referencia para as aquisições: "Quando o estoque pode assim ser conhecido e apto a ser exposto aos olhares do mundo, então a maneira de negociar com ele, tanto em casa como no exterior, será de chegar ao cerne tanto para o incremento de estoque, quanto para a melhoria de seu uso". (RLK, p. 19)

Mas não acaba por aqui. A interação constante com os membros da comunidade acadêmica é necessária quando entra no mérito das aquisições. Dury oferece, aqui, um segundo papel de mediador entre a informação e os usuário. Come feito, ele tem uma política de aquisições bastante interessante, pois vai alem das sugestões e pedidos dos membros da comunidade a que a biblioteca pertence. Existia, na Inglaterra da época, já a obrigação, por parte dos tipógrafos do Reino Unido e das Colônias, de enviar ua copia de todos os títulos impressos para as 
bibliotecas universitárias. É evidente, para Dury, que o bibliotecário não tem condições de ler tudo, nem de saber, exatamente, o que pode ou não ser integrado ao catálogo como aquisição: "é impossível, para um homem só, ler todos os livros para todas as faculdades, julgá-los pelo que nele vale. Nem tem qualquer um a habilidade de julgar sobre todos os ramos das ciências [...]". Recorre, assim, novamente, a uma prática que poderíamos definir de mediação entre os saberes e o acesso a eles. O bibliotecário, de fato, enviará essas publicações aos estudiosos das faculdades, que receberão os livros recebidos pela biblioteca com base nessa norma de "depósito legal", e serão eles os responsáveis pelo julgamento que irá ou não incluir aquele livro no catálogo das aquisições (ou, melhor, em seus suplementos).

Dury sabe, porém, que nem todo livro é totalmente interessante e que, às vezes, partes limitadas terão uma relevância para um determinado campo do conhecimento. Essa relevância pode ser apontada pelos estudiosos leitores que, ainda assim, não consideram a obra plenamente apropriada ou necessária para integrar o catálogo. Para Dury, todavia, se trata de livros gratuitos que, ainda que de maneira limitada, podem apresentar algo "útil", ao desenvolvimento do conhecimento. Propõe, assim, que esses livros sejam acolhidos na biblioteca em um espaço a eles reservado, para serem, também, colocados à disposição dos leitores. E assim, reocupado com a disponibilização dos textos, impõe que o bibliotecário elabore um segundo catálogo organizado em ordem alfabética, referente a essas publicações, com as anotações das partes de eventual interesse para as diferentes áreas: "O bibliotecário é obrigado a produzir o catálogo de todos os livros enviados para a universidade pelos tipógrafos".

Dury não esquece de criar mecanismos de comunicação e de controle, para que o bibliotecário tenha seu trabalho reconhecido e, ao mesmo tempo, fiscalizado. A cada ano, ele escreve, deve ser convocada uma reunião onde estarão presentes as autoridades da universidade, às quais o bibliotecário apresentará o relatório das atividades e das aquisições, documentadas através da eventual correspondência que possa tê-las acompanhadas, e o suplemento ao catálogo produzido em decorrência delas. Os materiais adquiridos serão, nesta ocasião, expostos para a apreciação e conhecimento das autoridades. 
Consciente dos perigos decorrentes da possibilidade de possíveis desvios de conduta do bibliotecário, para evitar que especule através da compra e venda dos livros da biblioteca, propõe que tenha um reembolso anual pelas despesas sustentadas ao longo do ano e, principalmente, por ser um estudiosos entre os estudiosos (e não um funcionário "genérico"), propõe que receba um salário equiparado ao dos colegas da universidade.

O esquema fundamentado na busca de sistemas de acesso através de múltiplas mediações realizadas pelo bibliotecário de Dury desaparece ao longo do tempo, privilegiando, nos estudos biblioteconômicos, enfoques ligados à organização como técnica não voltada diretamente para a mediação com os usuários ou, de qualquer maneira, que privilegia a eficiência pela padronização à qual o usuário deve se submeter sem poder se tornar protagonista de sua criação.

\section{CONSIDERAÇÕES FINAIS}

Somente em tempos bem recentes, graças à influência, de um lado, dos historiadores e, do outro, dos estudos sobre bibliografia de MCKENZIE (2001), de grande relevância e, todavia, ainda pouco citados no Brasil (CRIPPA, 2012), os estudos biblioteconômicos tem se interessado novamente por um passado em que bibliotecas e bibliotecários se inserem em um tecido social e cultural de produção e circulação do conhecimento, principalmente à luz dos estudos que, em nossa visão, não necessariamente são inovação, voltados para a organização da informação como elemento fundamental da mediação.

É nesse sentido que, talvez, uma reconstituição das idéias, dos procedimentos e das práticas históricos nas e das bibliotecas pode contribuir a ponderar em que medida nos deparamos com inovações e continuidades dentro das bibliotecas em suas relações fundamentais com o conhecimento, a informação e o papel que elas desempenham como meios de transmissão cultural.

Se consideremos, por exemplo, o sistema inovador proposto por Dewey, podemos observar que ele permite uma localização física com muita facilidade e uma ampliação quase ilimitada das classes. Todavia, ainda que tenha feito a felicidade de várias gerações de bibliotecários pela sua eficiência e praticidade basicamente mecânicas, dificilmente o usuário terá condições, sozinho, de recuperar 
as informações necessárias. Outras ferramentas catalográficas e, possivelmente, a decodificação por parte do próprio bibliotecário da representação numérica serão necessárias ao usuário.

Pensemos em outro grande nome da produção bibliográfica, Antonio Panizzi, que ideou e implantou o sistema catalográfico do British Musem ainda na primeira metade do século XIX. Em uma troca de correspondência, originada pela reclamação de um usuário, Panizzi (1846) expõe a excelência do funcionamento do catálogo. Reproduz, inclusive, a ficha de requisição que o usuário deve preencher, seguindo à risca o modelo do próprio catálogo (PANIZZI, 1846, p. 5). Caso o usuário preencha de maneira incorreta alguma parte (como autor ou titulo errados ou parciais), não caberá ao bibliotecário preencher a lacuna, e a responsabilidade da falta de satisfação recai sobre o usuário incapaz. Consideramos muito interessante observar os traços da biblioteconomia na perspectiva do papel da mediação nos textos do Panizzi, cuja obra é considerada um marco na sistemática catalográfica, pois nessa perspectiva se revelam as práticas de uma biblioteconomia pouco afeita à mediação realizada pelas interações entre bibliotecário e usuários alem daquela da elaboração bibliográfica. O usuário é responsável pela recuperação, pois o princípio do Panizzi é de que ele já sabe aquilo que está procurando. É o usuário que deve se adaptar plenamente às normas e às padronizações da biblioteca, enquanto o bibliotecário é aquele que realiza um instrumento não mais passível de ser criticado.

O século XIX, por essa ótica, parece se afastar de uma linha de raciocínio que envolve os bibliotecários e suas produções bibliográficas como construção colaborativa com os usuários em suas pesquisas e recuperação (como as referencias que Dury coloca sobre a linguagem e as anotações para localização, que devem ser o mais simples possível), para se aproximar de uma proposta de organização cada vez mais tecnicamente autônoma, prescindindo das exigências do próprio usuário, em uma proposta de biblioteca em que o bibliotecário é cada vez mais reprodutor de números já dados e o catálogo e suas padronizações não se apresentam como interface amigável para o público em maior ou menor medida "leigo".

Paradoxalmente, o acesso mediado pelo catálogo aparenta se tornar mais difícil quando o bibliotecário entra na lógica da padronização; o usuário tem a sua 
disposição um instrumento único, um catálogo de grande funcionalidade, desde que saiba previamente suas formas de manuseio. Não espanta, assim, que a personalidade de John Dury, que coloca para o bibliotecário um papel centralizado nas atividades de mediação, tenha desaparecido dos "mapas histórico" das bibliotecas enquanto meios de transmissão (fluxo, acesso, circulação, apropriação) cultural, privilegiando seu aspecto estático de guarda.

\section{REFERÊNCIAS}

BOTTASSO, Enzo. Storia della biblioteca in Itália. Milano: Bibliográfica, 1984.

BURKE, Peter. Uma história social do conhecimento: de Gutemberg a Diderot. Rio de Janeiro: Jorge Zahar, 2003.

CARICCHIO, Mario. John Dury, reformer of education against the radical challenge. In: Les Dossiers du Ghril: Libertinage, athéisme, irréligion. Essais et bibliographie. I Athées, spirituels, fidéistes. 2010. Disponível em: <http://dossiersgrihl.revues.org/3787>. Acesso em: 15 de jul. de 2014.

CHARTIER, Roger. A ordem dos livros: leitores, autores e bibliotecas na Europa entre os séculos XIV e XVIII. Brasília: UnB, 1999.

CRIPPA, Giulia. Robert Darnton: a história do livro como contribuição aos estudos bibliográficos. In: SANTAREM SEGUNDO, José Eduardo; SILVA, Márcia Regina da e MOSTAFA, Solange Pontel. (Orgs.). Os pensadores e a Ciência da Informação. Rio de Janeiro: E-papers, 2012.

DARNTON, Robert. A questão dos livros: passado, presente e futuro. São Paulo: Companhia das Letras, 2010.

DELUMEAU, Jean. Mil anos de felicidade: uma história do paraíso. São Paulo: Companhia das Letras, 1997.

DURY, John. The reformed librarie-keeper. Disponível em: <http://www.gutenberg.org/cache/epub/15199/pg15199.html>. Acesso em: 10 de jul. de 2014.

GINZBURG, Carlo. Chaves do mistério: Morelli, Freud e Sherlock Holmes. Em: ECO, Umberto; SEBEOK, Thomas. 0 signo de três. Campinas: Perspectiva, 2004.

NAUDÉ, Gabriel. Avvertenze per la costituzione di una biblioteca. Bologna: CLUEB, 1992. 

mediação da informação

PANIZZI, Antonio. On the supply of printed books from the library to the reading room of the British Museum. London; C. Whittingham. 1846. Disponível em: $<$ https://archive.org/details/onsupplyprinted00panigoog >. Acesso em: 15 de jul. de 2014.

SABBA, Fiammetta. La Bibliotheca Universalis di Conrad Gesner: monumento da cultura européia. Roma: Bulzoni, 2012.

SERRAI, Alfredo. Conrad Gesner. Roma: Bulzoni, 1990.

SERRAI, Alfredo. Storia della bibliografia II: le enciclopedie rinascimentali (II), bibliografi universali. Roma: Bulzoni, 1991.

\section{Title}

Some treatises on libraries as sources for an history of organization to mediate information

\section{Abstract}

Introduction: Historical reflection on the nature of the field of knowledge and information organization that dislocates the focus of a traditional reading of the history of libraries and librarians in search of a critical and comparative picture of the logics of informational mediation

Objective: To cover an itinerary of study that uncurls between known and less known sources, such as the Gesner's Bibliotheca Universalis and the John Dury's Reformed Librarie-Keeper, reading and, sometimes, newly intrpretating them, trying to disclose stages and significant moments in the construction and the development of the ideas that produced and materialized forms of bibliographical and librarianship procedures of mediation.

Methodology: Use of sources and critical revision of literature.

Results: The XIX century discloses a removal of a reasoning line that involves librarians and their bibliographical productions as collaborative constructions with users in their researches and recoveries, while the $\mathrm{XVI}$ and $\mathrm{XVII}$ centuries disclosed a concern with the peculiarities of the knowing subjects, but, in first place, their ways and forms of acquiring information and knowledge.

Conclusions: The library science studies, through the study of the past, in which libraries and librarians were interwoven in social and cultural fabrics of production and circulation of knowledge, can develop a passage that, facing the organization of the information, discovers the weight it possesses as basic element of mediation.

Key words: Mediation. Library science. Bibliography. Conrad Gessner. John Dury.

\section{Título}

Algunos tratados en bibliotecas como fuentes para la historia de la organización para la mediación de la información. 

mediação da informação

\section{Resumen}

Introducción: Reflexión histórica sobre la naturaleza del campo de la organización del conocimiento y de la información que disloca el foco de una lectura tradicional de la historia de bibliotecas y de bibliotecarios adentro la busca de un cuadro crítico y comparativo de las lógicas de la mediación del informacional

Objetivo: Cubrir un itinerario del estudio que si desenrosca entre las Fuentes sabidas, como la Bibliotheca Universalis de Gesner y el Reformed Librarie-Keeper de Juan Dury, en vista de su lectura y, a los tiempos, relectura, que divulga a las etapas y a los momentos significativos en la construcción y el desarrollo de las ideas que si está tenido producido y materializado en las formas de procedimientos bibliográficos y de la ciencia de la biblioteca vueltos a la mediación.

Metodología: Uso de las fuentes e revisión crítica de la literatura.

Resultados: El siglo XIX divulga un retiro de una línea del razonamiento que implique a bibliotecarios y sus producciones bibliográficas como construcción colaborativa con los usuarios en su investigación y recuperación, donde el siglo XVI y XVII divulgaron una preocupación con los particularidades del sujeto experto, pero, en el primer lugar, con sus maneras y formas de adquirir el conocimiento.

Conclusiones: Los estudios de ciencia de la biblioteca, con el estudio del pasado donde bibliotecas y bibliotecarios se encuentran dentro de una tela social y cultural de la producción y de la circulación del conocimiento, pueden desarrollar un paso que, vuelto hacia la organización de la información descubra el peso que esa tiene como elemento básico de la mediación.

Palabras clave: Mediación. Biblioteconomia. Bibliografía. Conrad Gesner. John Dury.

Recebido em: 15.07.2014

Aceito em: 05.10.2014 